\title{
Caproni TRADUZIDO: UM OLHAR SOBRE OS PARATEXTOS
}

\author{
Fabiana Vasconcellos Assini \\ LUIZA KaVISKI Faccio \\ Patricia Peterle*
}

RESUMO: A intenção deste artigo é refletir sobre a recepção do poeta italiano Giorgio Caproni (1912-1990) no Brasil a partir da primeira antologia publicada no país dedicada ao poeta, A coisa perdida: Agamben comenta Caproni, publicada em 2011 pela Editora da Universidade Federal de Santa Catarina. Busca-se a partir da obra, analisar os paratextos nela presentes, tentando compreender a imagem do poeta, ainda pouco conhecido se comparado a outros poetas italianos contemporâneos como Eugenio Montale (1896-1981). Refletir também acerca da importância dos elementos paratextuais para a motivação da aquisição e leitura de um livro. Elementos que, muitas vezes, passam despercebidos para o público, mas que podem se tornar peças fundamentais aos estudiosos da literatura, sobretudo da literatura traduzida.

PALAVRAS-CHAVE: literatura traduzida; poesia italiana; recepção; Brasil; Giorgio Caproni; paratexto.

ABSTRACT: Con questo articolo si intende riflettere sulla ricezione in Brasile del poeta italiano Giorgio Caproni (1912-1990), a partire dalla prima antologia che gli è stata dedicata in questo paese, A coisa perdida: Agamben comenta Caproni, pubblicata nel 2011 dalla Editora da Universidade Federal de Santa Catarina. Partendo dall'opera, si cerca di analizzare i paratesti per capire l'immagine del

* Universidade Federal de Santa Catarina, Florianópolis (Brasil) - fabi.assini@gmail.com / lkfaccio@gmail.com / patriciapeterle@gmail.com

Processo n.2013/20971-0 Fundação de Amparo à Pesquisa do Estado de São Paulo (FAPESP)

DOI: http://dx.doi.org/10.11606/issn.2238-8281.v0i33p111-120 
poeta, ancora poco conosciuto, se confrontato con altri poeti italiani contemporanei come Eugenio Montale (1896-1981). Si riflette inoltre sull'importanza degli elementi paratestuali nell'acquisto e lettura di un libro, elementi che molte volte passano inosservati, ma che possono diventare fondamentali per gli studiosi di letteratura, soprattutto di letteratura tradotta.

PAROLE CHIAVE: letteratura tradotta; poesia italiana; ricezione; Brasile; Giorgio Caproni; paratesto.

ABSTRACT: This article intends to reflect about the reception of the Italian poet Giorgio Caproni (1912-1990) in Brazil based on the anthology A coisa perdida: Agamben comenta Caproni, published by Universidade Federal de Santa Catarina in 2011 and dedicated to the poet. Having the anthology as a point of start, the main objective is to analyse the paratext in it presented, trying to comprehend the image of the poet in the country, which is still not well known compared to other contemporary italian poets such as Eugenio Montale (1896-1981). To reflect about the importance of the paratext elements for the purchase and reading of the book is also a goal. Elements, that most of the time go unnoticed by the public, but which may become a key piece to the literary scholars, especially of translated literature.

KEYWORDS: Translated Literature; Italian poetry; Reception; Brazil; Giorgio Caproni; Paratext. 
livro tal qual o conhecemos hoje é um modelo bastante recente. Apesar disso, já estamos tão acostumados com algumas informações tendo maior destaque que outras (como o título, nome do autor e editora, por exemplo), que raramente nos questionamos sobre as escolhas dos mesmos, sobre suas posições na capa e quarta-capa, e às vezes ignoramos a presença (ou ausência) de sumários, prefácios e agradecimentos. Elementos esses que podem revelar informações não tão visíveis assim.

O estudo desses elementos, conhecidos como paratextos (GENETTE, 2009), que podem se tornar peças fundamentais para quem estuda literatura, inclusive, para o estudo da literatura traduzida. Refletir sobre a recepção de um autor estrangeiro no Brasil, por exemplo, pode incluir a análise do objeto físico, do livro. Objeto que se configura justamente por meio desses elementos paratextuais.

Esse é, portanto, o objetivo deste artigo. Ir além da reflexão acerca da recepção do poeta Giorgio Caproni no Brasil, isto é, analisar os elementos paratextuais presentes na única antologia publicada no país dedicada ao poeta italiano. A antologia intitulada A coisa perdida: Agamben comenta Caproni, será estudada a partir do livro Paratextos editoriais (2009), de Gérard Genette, considerada uma importante obra para compreender esses elementos que acompanham os livros.

Antes de entrarmos, de fato, na análise da antologia, é interessante esclarecer o que seria paratexto. Podemos dizer que o paratexto é constituído por todos os elementos que estão além 
do texto, por exemplo: capa, quarta-capa, lombada, título, editora etc., e que podem, de certa forma, contribuir para motivar a aquisição e leitura de um livro.

Genette divide o paratexto em duas seções: peritexto e epitexto. O primeiro seria o que está "em torno do texto, no espaço do mesmo volume, como o título ou o prefácio, e, às vezes, inserido nos interstícios do texto, como os títulos de capítulo ou certas notas" (GENETTE, 2009 , p.12); enquanto o segundo faz referência à "parte externa do livro: em geral num suporte midiático [...], ou sob a forma de uma comunicação privada [...]" (GENETTE, 2009, p.12). Ou seja, um está direcionado para o próprio livro, enquanto o outro observa os recursos externos, que não estão presentes no objeto físico.

Neste artigo, a intenção é observar os peritextos. Porém selecionamos apenas aqueles presentes na capa e quarta capa. Ressaltando que estudá-los nos permitirá ter uma visão também do interior do livro e suas divisões, sem esquecer de pensar em como o poeta é inserido no país, já que essa é a primeira obra de Caproni publicada no Brasil.

Giorgio Caproni nasce em uma cidade da Toscana, Livorno, em 1912. Aos 10 anos, muda-se com a família para Gênova, na Ligúria, cidade com a qual cria profundos laços. Sua coletânea de estreia é Come un'allegoria (1936), publicada pouco tempo depois da morte de sua noiva, Olga Franzoni. A perda de sua amada marca profundamente a escrita caproniana, assim como a perda da mãe, anos mais tarde.

Em 1938, Caproni casa-se com Rina Rettagliata, e seu segundo livro é publicado: Ballo a Fontanigorda. Em seguida temos: Finzioni (1941) e Cronistoria (1943). Já em meados dos anos 40, Caproni e sua família mudam-se para Roma, cidade que oferece melhores condições financeiras para sua carreira de professor primário e um maior contato com a produção cultural e literária italiana daquele momento.

Participa da Segunda Guerra Mundial e da Resistenza. E nesse período também faz diversas colaborações em revistas e jornais, onde publica, sobretudo, artigos sobre poesia e tradução, atividade que também exerceu com maestria.

Apesar de publicar Il passaggio d'Enea (1956), Il seme del piangere (1959) e Congedo del viaggiatore cerimonioso \& altre prosopopee (1965), será com a coletânea intitulada Il muro della terra (1975) que conquistará o reconhecimento da crítica e se tornará objeto de estudo. Seguida a ela, tem-se: Il franco cacciatore (1982) e Il Conte di Kevenhüller (1986), obras que formam o chamado "último Caproni”, revelando um poeta mais seco, onde as palavras já não são suficientes para conseguir se expressar, e nas quais a não existência de Deus é questionada. 
Giorgio Caproni morre no final do século, em 1990, em Roma. Um ano após seu falecimento, é publicada a coletânea Res Amissa (1991), organizada pelo filósofo Giorgio Agamben, seu amigo. Foi um poeta que praticamente atravessou todo o século XX, que teve mais de 10 obras poéticas publicadas, mas que só aparece aqui no Brasil no século XXI.

Pensar no objeto-livro como um todo, analisar determinados elementos e refletir sobre eles, nos possibilita pensar no livro como um grande arquivo. Um arquivo que contém informações não tão visíveis. Jacques Derrida, em Mal de arquivo: uma impressão freudiana (2001), nos oferece uma noção de arquivo, pensando então no livro como um local onde se arquiva informações, onde se preserva um conteúdo. E é a partir de tal arquivo que buscamos informações "invisíveis", que vão além do texto escrito. Chegando assim, aos paratextos, informações que muitas vezes são ignoradas num primeiro olhar.

O livro é, portanto, um documento. Um documento capaz de fornecer inúmeras informações que ultrapassam o texto. Informações sobre o público-alvo, sobre o período histórico do país de chegada, e até mesmo conhecer um pouco mais sobre a editora, são apenas alguns exemplos.

A antologia: A coisa perdida: Agamben comenta Caproni, foi publicada em 2011, pela Editora da Universidade Federal de Santa Catarina (Ed.UFSC). Além de conter uma seleção de poemas que perpassam pelas principais obras poéticas de Giorgio Caproni, organizados e traduzidos por Aurora Fornoni Bernardini, a antologia ainda conta com um sumário, uma nota introdutória escrita pela organizadora e um texto de Giorgio Agamben, traduzido para o português.

O primeiro elemento paratextual a ser analisado é a capa. Segundo Genette, a capa nem sempre vai ser a primeira manifestação do livro que é oferecida à percepção do leitor, pois eventualmente pode haver alguma sobrecapa ou cinta (GENETTE, p.30), o que ocorre frequentemente em best-sellers e livros que ganham uma adaptação cinematográfica ou passam a fazer parte de uma coleção específica. Em relação à sobrecapa, também é bastante comum encontrarmos em livros de capa dura, sejam eles teóricos ou não.

Visto que tal antologia não pertence à categoria de best-sellers, até porque não faz parte da categoria chamada "literatura de consumo", o livro não é acompanhado por uma sobrecapa ou uma cinta. Aliás, se pensarmos que a capa é o que normalmente atrai o público, é possível perceber que essa capa não é nem um pouco atraente. A cor azul-claro não oferece nenhum destaque e pode dar a ideia de um livro sério, restringindo, de certo modo, o público-leitor.

Um livro de poesia (como é o caso dessa antologia) não precisa ser pouco atraente. Essa 
"falta" de atrativo pode parecer contribuir com a ideia de que a poesia é difícil, séria, restrita a poucos leitores, não podendo ser agradável, divertida e fácil. A poesia pode ser atraente como, por exemplo, Toda poesia (Companhia das Letras, 2013) e Vida (Companhia das Letras, 2013), de Paulo Leminski (1944-1989), poeta curitibano. Ambos os livros possuem uma capa que fica facilmente destacada entre outros livros. Uma é de um laranja forte com o título em negrito, enquanto a outra possui um vivo tom de amarelo, mantendo o título em negrito, ganhando bastante visibilidade sobre a cor da capa.

Isso nos mostra que é possível publicar um livro de poesia atraente. É claro que as editoras (Ed. UFSC e Companhia das Letras) são diferentes se pensarmos em seus catálogos. Uma está, obviamente, mas voltada para a academia; a outra, a um público muito mais amplo. Porém, é interessante pensar que a editora universitária tem outros livros de poesia, que trazem a poesia como texto principal, mas nem por isso eles são menos atraentes. Como é o caso de $O$ homem e os animais: poemas de Umberto Saba, (2014, com organização de Patricia Peterle e Lucia Wataghin; tradução de Aurora F. Bernardini), que possui uma capa de tom arroxeado e detalhes em rosa. Ou seja, a capa de A coisa perdida poderia ter mais destaque e ser, inclusive, de outra cor, pois o livro não pertence à nenhuma coleção, o que pode, eventualmente, determinar a necessidade de uma padronização de capa para ser possível identificar a coleção dos demais livros da editora.

Após pensar na capa como um todo, podemos isolar alguns elementos para tentar entender de que modo o poeta italiano se apresenta ao público brasileiro. Como é possível observar, não existem muitas informações na capa, tendo entre elas: o título, a responsável pela organização e tradução, e a editora. Começaremos pelo título.

O crítico francês G. Genette, divide sua obra em treze capítulos, sendo que um deles é dedicado inteiramente aos títulos. Sobre eles, Genette diz:

Um dos fundadores da titulologia moderna, Leo H. Hoek, escreveu com correção que o título tal qual o entendemos hoje é, de fato, pelo menos diante das intitulações antigas e clássicas, um objeto artificial, um artefato de recepção ou de comentário, imposto arbitrariamente pelos leitores, pelo público, pelos críticos, pelos livreiros, pelos bibliógrafos [...]. (GENETTE, 2009, p.55)

Ou seja, o título é artificial, objetivando atingir um público-alvo. Porém, isso não significa 
que ele deva ser sempre claro sobre o conteúdo total do livro. O que é, de fato, observado no título em análise: A coisa perdida: Agamben comenta Caproni. Folheando rapidamente o livro, ou olhando imediatamente o sumário, percebe-se que a maior parte da antologia é destinada aos poemas de Giorgio Caproni. Enquanto no título, uma possível primeira impressão é de que se trata de uma leitura crítica feita por Agamben a respeito de Caproni. O texto de Agamben ocupa, na verdade, somente 15 páginas do livro. Não existe nenhuma indicação na capa de que se trate de uma antologia poética.

Aliás, se verificarmos a ficha catalográfica, o presente livro está na categoria de "crítica e interpretação", além de "poesia italiana - História e crítica". É claro que não se pode negar a presença do comentário de Giorgio Agamben, porém, pelo conteúdo apresentado, parece que não é apenas um livro de crítica e interpretação; ele é, sobretudo, um livro de poesia.

Tentando refletir um pouco na questão "título" e "subtítulo", vemos que o título A coisa perdida vem acompanhado pelo subtítulo Agamben comenta Caproni. O subtítulo parece existir para auxiliar na compreensão do próprio título, uma vez que o texto do filósofo trata da coisa perdida, o res amissa, título da coletânea caproniana póstuma. ${ }^{1}$

Interessante dizer que só poderão compreender realmente o título aqueles que já conhecem o poeta italiano, ou aqueles que lerão essa obra. Conseguir ter uma mínima ideia do que significa o título, significa ler tanto a nota introdutória feita pela organizadora, Aurora Fornoni Bernardini, quanto o texto de Giorgio Agamben.

Se por um lado, o título (e subtítulo) parece não cumprir a função determinada por Genette:

a função, ou, melhor, as funções do título, parece ter-se estabelecido uma espécie de vulgata teórica, que Charles Grivel formula mais ou menos como segue: 1. identificar a obra; 2. indicar seu conteúdo; 3. valorizá-lo, [...]. (GENETTE, 2009, p.73).

Por outro, consegue manter sua capacidade de sedução, uma vez que o fato de não dizer

1 Aliás, interessante observar que a coletânea caproniana que contém mais poemas traduzidos é justamente aquela publicada postumamente, com 29 poemas contemplados. Na sequência estão: Il franco cacciatore, com 23 ; Il Conte di Kevenhüller, 14; Come un'allegoria, 11; Il Passaggio d'Enea e Il muro della terra, com 9 poemas cada; Cronistoria, 8; Ballo a Fontanigorda, 5; Congedo del viaggiatore cerimonioso, 4; e por fim, Finzioni e Il seme del piangere, com 3 poemas traduzidos. 
muita coisa pode ser visto como um ponto positivo para atrair a atenção do público, despertar a curiosidade a ponto de fazer com que o leitor busque pistas no interior do livro para descobrir o que seria "a coisa perdida". Além do mais, posicionar o nome do poeta no final pode facilitar o leitor na busca por referências, já que por ser o último nome do título, seria o primeiro a ser lembrado.

A identificação da obra será colocada por Genette como função obrigatória do título, ao passo que as outras duas são de caráter opcional. Então, podemos dizer que o título não identifica de maneira completa a obra, pois enfatiza somente o texto de Agamben, mas também não indica seu conteúdo, que são os poemas de Giorgio Caproni. A função de valorização seria a que melhor se encaixa nesse título, já que utiliza do nome do filósofo italiano (figura com um possível maior reconhecimento se comparado ao poeta) como uma ponte para apresentar Caproni.

Inserir o nome do filósofo antes do poeta, apesar do segundo estar presente na maior parte da antologia, reforça a teoria de que Giorgio Agamben é mais conhecido ao público brasileiro do que Giorgio Caproni, contribuindo assim, para uma maior circulação deste. Se o nome de Agamben fosse retirado do subtítulo, e restasse apenas o do poeta, talvez a antologia ficasse restrita a um número muito reduzido de possíveis leitores.

Outro detalhe a se observar é a cor de destaque no título. O título em si é escrito em cor preta, mas os sobrenomes de Agamben e Caproni, não. Ambos aparecem na cor branca, ganhando destaque com o restante em preto. Ou seja, podem ser vistos como pontos atraentes do título. Buscam atrair além do público geral, aqueles que já conhecem e são leitores de Agamben e/ ou Caproni.

O segundo elemento presente na capa e que também é destacado com a cor branca, é a editora. E que pode estar conectada diretamente ao título. A Editora da Universidade Federal de Santa Catarina publica livros que são destinados para o público universitário, ou seja, um grupo mais reduzido e específico do que o público em geral, que frequenta as diversas livrarias. Sendo o poeta ainda pouco conhecido no meio acadêmico brasileiro (e acredito ser interessante dizer que isso está mudando pouco a pouco), inserir Agamben no início pode ampliar os locais de circulação desse livro, uma vez que o filósofo está presente em outras áreas, como na área da filosofia e do direito.

Tratamos até aqui a respeito da capa, mas evidentemente, ela não é o único elemento paratextual disponível em um livro. Como dissemos no início deste artigo, o outro elemento que nos chamou a atenção foi a quarta capa. 
Para Genette, a quarta capa surge como um lugar estratégico (GENETTE, 2009, p.28) para atrair o leitor, não apenas para a leitura do livro em questão, mas como um espaço de divulgação para outros lançamentos da editora ou do autor, já que pode conter, por exemplo, notas biográficas, citações da imprensa etc. Porém, na quarta capa de A coisa perdida, encontramos apenas um poema, o código de barras e o símbolo da Pró-Reitoria de Pós-Graduação da Universidade Federal de Santa Catarina (PRPG).

Dentre esses componentes, o que aparece mais evidente é, sem dúvida, o poema central. Entretanto, é curioso notar que não existe mais nenhuma informação além do pequeno texto e seu título: "As facas". O que nos leva a refletir: será que o público, tendo acesso apenas à parte externa do livro e, consequentemente, ao título, consegue associar o poema a Giorgio Caproni? Uma das possíveis reflexões é de que o poema foi inserido na quarta capa de modo a antecipar ao leitor algo sobre o conteúdo do livro, ou para indicar que, de certo modo, o comentário de Agamben perpassa por aquele determinado poema, presente na coletânea Il muro della terra (1975), obra que inicia essa última fase caproniana, sendo seguida por outras duas obras (Il franco cacciatore e Il Conte di Kevenhüller) e concluída com Res Amissa.

Encontrar e refletir acerca dos elementos paratextuais não é uma tarefa simples. E acreditamos que é um caminho sem volta. A partir do momento em que nos damos conta de todas as possíveis informações que não encontramos em um primeiro olhar, torna-se impossível ignorar a presença desses componentes outra vez. A obra de Gérard Genette foi a peça fundamental para abrir as portas desse novo universo de informações.

Após a análise proposta neste artigo, tendo como foco a capa e quarta capa, podemos concluir que o nome do filósofo, Giorgio Agamben, funciona como um impulsionador para que o nome do poeta, Giorgio Caproni, alcance um público maior. Uma vez que Caproni ainda não conquistou grande reconhecimento no Brasil, sobretudo no meio acadêmico, essa associação é válida para um primeiro contato.

Observar esses elementos na primeira, se não única, obra destinada aos poemas de Giorgio Caproni, contribui para compreender de que modo o poeta é apresentado ao público brasileiro. A primeira observação é de que ainda é um poeta acadêmico, já que os livros publicados pela Editora da Universidade Federal de Santa Catarina circulam entre os ambientes acadêmicos e não são facilmente encontrados nas livrarias. Ou seja, os interessados em poesia italiana que não estão no meio acadêmico não terão fácil acesso aos poemas de Caproni.

Outra observação é que parece que o livro, por si só, não atrairia o público-alvo se na capa 
houvesse apenas a indicação de que se trata de uma antologia poética de autoria de Giorgio Caproni.

Um possível futuro estudo pode ser desenvolvido sobre os poemas selecionados para tradução de Aurora Fornoni Bernardini. Anunciamos brevemente a quantidade de poemas traduzidos de cada obra poética, porém pode-se aprofundar este estudo, tentando estabelecer uma relação entre os poemas escolhidos e as obras em si. Será que eles são suficientes para representar cada obra?

Por fim, este artigo buscou trazer a reflexão sobre alguns dos inúmeros elementos paratextuais destacados por Gérard Genette, pensando na recepção de um poeta italiano contemporâneo no Brasil, uma vez que o mesmo ainda não é tão conhecido, ou até mesmo estudado, como outros poetas do período.

\section{Referências}

CAPRONI, G. A coisa perdida: Agamben comenta Caproni. Organização e tradução de A.F. Bernardini. Florianópolis: Ed. da UFSC, 2011.

DERRIDA, J. Mal de Arquivo: uma impressão freudiana. Trad. C.M. Rego. Rio de Janeiro: Relume Dumará, 2001.

GENETTE, G. Paratextos editoriais. Trad. A. Faleiros. Cotia, SP: Atêlie Editorial, 2009.

PEREIRA, M.R.A. "Leitura dos paratextos de Toda poesia e Vida, de Paulo Leminski, e Bili com limão verde na mão, de Décio Pignatari”. Intercom - Sociedade Brasileira de Estudos Interdisciplinares da Comunicação. XXXVIII Congresso Brasileiro de Ciências da Comunicação - Rio de Janeiro, RJ - 4 a 7/9/2015. http://portalintercom.org.br/anais/nacional2015/resumos/R10-1525-1.pdf - Acesso: 13/10/2016.

SABA, U. O homem e os animais: poemas de Umberto Saba. Organização de Patricia Peterle e Lucia Wataghin. Trad. A. F. Bernardini. Florianópolis: Ed. da UFSC, 2014.

Recebido em 11/12/2016

Aprovado em 05/04/2017 